\section{From diet to behaviour: exploring environmental- and animal- conscious behaviour among Austrian vegetarians and vegans}

From diet to behaviour

Ursula Ploll

Institute for Food and Resource Economics, University of Bonn, Bonn, Germany, and Tobias Stern

Institute of Systems Sciences, Innovation and Sustainability Research, University of Graz, Graz, Austria

\begin{abstract}
Purpose - Vegetarian and vegan dietary practices have recently moved from being marginal activities to occupying a more mainstream position. While the reasons for this have been analysed by many researchers, the extent to which the underlying motives may influence other behavioural contexts remains relatively unexplored. The present research thus analyses the degree to which vegetarians and vegans also act in an environmental and animal-conscious manner.

Design/methodology/approach - A self-administered survey was conducted among omnivores, conscientious omnivores, vegetarians and vegans in Austria. The research design is embedded in an extended version of the theory of planned behaviour (TPB). A mixed-mode sampling strategy resulted in 556 completed surveys.

Findings - The TPB correlation analysis shows that there are significant relations between dietary motives, subjective norms, attitudes, behavioural intentions and the behaviour in question. When considering all dietary groups, the results indicate that the differentiation in behaviour is impacted by dietary identity: the stricter the diet, the stronger the behaviour related to animal-wellbeing and environmental protection.

Originality/value - First, this research evaluated motivational drivers through a pairwise comparison, which resulted in strength factors instead of single motivational driver. Second and foremost, this research draws a connection between dietary categories and the wider behavioural implications related to these identities and their underlying motivational drivers.
\end{abstract}

Keywords Vegetarianism, Veganism, Behaviour, Motives, Theory of planned behaviour

Paper type Research paper

\section{Introduction}

As one of the universal and basic human needs, nutrition and dietary choices contribute significantly to environmental impacts by playing an important role in many global processes (e.g. Campbell-Arvai et al., 2014; Pimentel et al., 2008; Tanner et al., 2004; Wansink and Sobal, 2007). Due to the impact that food practices may exert, a number of consumer-based strategies have arisen in an attempt to alter the overall structure of food production. Vegetarianism and veganism, for example, have often been identified as such bottom-up movements, and the

(C) Ursula Ploll and Tobias Stern. Published in British Food Journal. Published by Emerald Publishing Limited. This article is published under the Creative Commons Attribution (CC BY 4.0) licence. Anyone may reproduce, distribute, translate and create derivative works of this article (for both commercial and non-commercial purposes), subject to full attribution to the original publication and authors. The full terms of this licence may be seen at: http://creativecommons.org/licences/by/4.0/legalcode

We would like to thank Heidrun Petritz for her valuable support during the data collection at the very beginning.

Funding Details: No specific funding was provided for this research by agencies in the public, commercial, or not-for-profit sectors.
Received 12 June 2019 Revised 26 November 2019 18 January 2020 Accepted 19 March 2020 
BFJ

122,11

number of such phenomena appears to be increasingly on the rise (Ruby et al., 2013; Stiles, 1998). While clear statistics concerning the extent of the vegetarian or vegan population are hard to come by, figures commonly reported in various studies show that around $1.0 \%$ of the population in Portugal, $10.0 \%$ in Italy, $11.0 \%$ in Germany and $2.4 \%$ in North America, are vegetarian (Barr and Chapman, 2002; Rothgerber, 2015; YouGov Deutschland, 2014). Phillips (2005) also claims that there has been a minor but continual increase in vegetarians and vegans. In 2013, the Institute for Empirical Social Research (Institut für empirische Sozialforschung GmbH, IFES), estimated that the share of vegetarians in Austria increased from $3.0 \%$ to $9.0 \%$ of the population between 2005 and 2013 (APA-OTS, 2013). Particularly in recent years, there has been an increase in the amount of attention received by vegetarian and vegan dietary practices. In this spirit, the aim of this paper is to capture other behavioural commitments that appear to be connected to the vegetarian or vegan diet.

The different motivational drivers that cause people to become a vegetarian or a vegan are an important aspect, which has also been highlighted in previous research (Beardsworth and Keil, 1992; Forestell et al., 2012; Fox and Ward, 2008a; Radnitz et al., 2015; Rozin et al., 1997; Stiles, 1998). In order to facilitate further understanding of the scope of the vegetarian and vegan identity there is a need to pinpoint what the various motives mean with respect to behavioural contexts next to the field of nutrition. The motives underlying dietary practices can have a number of behavioural implications. Among research which deals with behaviour as their subject of research interest, the Theory of Planned Behaviour (TPB) has gained a prominent role in academia (Sniehotta et al., 2014). The title of the theory indicates that it deals with consciously planned behaviour, such as dietary intake. Especially vegetarian and vegan diets are conscious dietary regimes driven by certain motivational drivers. In this research, motives and related behaviours are investigated within the framework of the TPB, while also going beyond the model's specification by weighing in motivational drivers. Data was collected through a self-administered survey.

Because of the assumption that motivational drivers are based on general ethical considerations, we expect that these underlying ethical reflections are not restricted to a dietary implementation, but instead are applicable in other behavioural spheres. This will also be tested and reflected in the analysis of the TPB, where motivational drivers are included as a factor influencing other behavioural spheres. If participants indicate strong motivational drivers, then also the behavioural commitment is expected to be strong. Second, within that line of thought, we hypothesized that the dietary identity also influences the degree of behavioural commitment. We suspect, that a stronger level of dietary restriction (as per definition of the dietary groups) correlates with a stronger behavioural commitment. This hypothesis is based on the assumption that participants who engage in restricted diets have shown a stronger engagement to act based on their convictions.

Essentially, the contribution of the present research is twofold. On the one hand, this research narrows the scope of the respective identities based on vegetarian and vegan diets by providing new insights into the relationship between motives and the expression of the underlying ethical considerations in a wider, behavioural context. On the other hand, distinctive features and unique behavioural patterns of vegetarians and vegans are outlined in comparison to the average omnivore. On a theoretical note this paper weighs in on the discussion of the TPB by including motivational drivers as consciously chosen factors influencing behaviour.

\section{Vegetarian definitions and concepts}

\subsection{Vegetarian and vegan characterizations}

Through careful selection of certain products, and the exclusion of mainly animal-derived products, the vegetarian or vegan diet alters the basis of the product value chain. The most 
common conception of vegetarianism was originally developed by Beardsworth and Keil (1992) in the form of the vegetarian scale. Here, the authors capture the variety of dietary patterns on a scale ranging from least to most strict (1992, p. 263). Figure 1 depicts the vegetarian and vegan types and includes the four dietary groups used in the research design.
From diet to behaviour

\subsection{Behaviour and motives}

The motives behind the commitment to a vegetarian or vegan diet are likely to be just as diverse as the associated impacts of following such a diet. Previous studies of behavioural activities related to vegetarianism and veganism have tended to limit themselves to nutrition. Only relatively few scholars have researched the connection between dietary choices and certain lifestyle choices (i.e. Fox and Ward, 2008a; Radnitz et al., 2015). Assuming that individuals become vegetarian or vegan due to a certain motive, one may also ask whether this motive finds expression in other activities.

The most common motives for an individual to change to a vegetarian or vegan diet have already been established in previous research (Fox and Ward, 2008b; Peattie, 2010; Rozin et al., 1997; Ruby et al., 2013). Health and ethical considerations form the two main clusters. This binary classification system captures one important notion: the difference between intrinsic and extrinsic orientation. An individual whose motivation is driven by healthrelated reasons is concerned about his/her own well-being. On the other hand, for an individual whose motives lie in ethical considerations, it is the quality of exterior conditions, which are of concern. The present research focuses on ethical motives, since it is assumed that the concern for certain external conditions is not confined to dietary choices alone. Indeed, concerns for exterior well-being encompass a wide range of activities, all of which may be a source of motivation. Furthermore, religious doctrine restricting dietary patterns was specifically excluded as a factor in this study. Strong restrictions with regard to meat and fish consumptions are practiced in, for example, Hinduism or Buddhism (Phillips, 2005). However, Austrian society is predominantly shaped by Catholic religion, where dietary restrictions play a limited role in religious practice.

\section{Methods}

Behavioural patterns and commitments form the centre piece of the research design. The TPB has attained overall academic acceptance as a conceptual model for capturing behaviour. The aim of the TPB is to explain human behaviour via the role played by consciousness (Ajzen, 1991, 2011). Vegetarian and vegan diets can be described as such a conscious dietary behaviour. In contrast to other conscious behaviour, vegetarians and vegans uniquely base their dietary behaviour on certain motivational drivers. This highlights

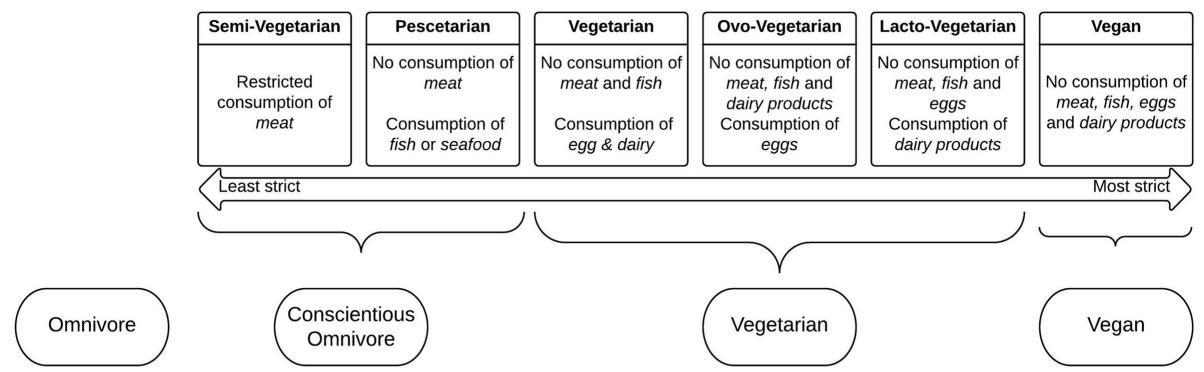

Figure 1.

Vegetarian scale including clustering of dietary groups (adopted from Beardsworth and Keil, 1992)

Source(s): adopted from Beardsworth and Keil, 1992 
BFJ

122,11

the need to also weigh in motivational factors when researching behaviour related to vegetarians and vegans. Studies, which applied the TPB, found a variety of limitations and varying degrees of predictive power. Subsequently, several researchers decided to add further concepts to the model in order to increase the precision of the theoretical framework (Aertsens et al., 2009; Berndsen and Van Der Pligt, 2004; Connor and Armitage, 1998; Fleskens and Jorritsma, 2010; Peattie, 2010; Povey et al., 2001; Vermeir and Verbeke, 2006). Hence, with respect to the present study, key conceptual elements have been taken from the $\mathrm{TPB}$, and then augmented to include (the strength of) the relevant motives.

\subsection{Motives}

Previous scholarly work identified several key motives. These were reduced by the researcher to a final selection comprising the following four overarching motives: health, animals, environment and taste. As several motives can simultaneously influence the decision process, a pairwise comparison of the different motives was included in the questionnaire. In this way, the relevance of several motives could be accounted for in relation to each other. This approach was derived from the analytical hierarchy process (AHP). The process was first thought of by Thomas L. Saaty as a means of breaking down complex problems into several tangible elements (Mateo, 2012). These tangible elements were then used for pair-wise comparison and thus facilitated relative measurement (Saaty, 1996). In the present research, the application of the AHP was limited to the comparison of the motives and the calculation of the strengths of these motives. Ultimately, not a single motive was included in the design, but the strength of each motive was included as a separate variable in the extended TPB.

\subsection{Participants and procedure}

Before creating the sample through various sampling strategies, a pre-test was conducted at a fair, themed around vegan and vegetarian products and lifestyle in Graz. Owing to the cooperation of the hosts, it was possible to set up a stand at a fair for the pre-test. A total of 20 participants filled out the survey right there and provided immediate verbal or informal feedback.

The main part of the data collection was executed using the software LimeSurvey. With this online software, the survey was forwarded and accessed through an URL; i.e. online distribution was also used. An internet-based survey has several advantages and disadvantages; some groups are easier to reach through online means (Nosek et al., 2002). A diverse sampling strategy was used to reach as many vegetarians and vegans as possible. Although dietary choice represents a unifying characteristic in the population, this does not necessarily lead to any form of gathering or focal point of vegetarians and vegans. Altogether, using a multi-mode sampling strategy, a diverse mix of participants was reached. See Table 1 for an overview.

The complete sample was based on the data of 556 participants, with a strikingly high number of female participants $(79.70 \%)$. The majority of this sample was in their mid to late 20 s (mean $=28.45$ years old, mode $=24.00$ years), $50.00 \%$ were between 22 and 31 years old. Given the sampling method, the average age structure is related to the fact that $56.30 \%$ of the participants (the average is 26.55 years old) were reached through the university e-mail distribution system. For an overview of the main sample characteristics see Table 2.

The noticeable characteristics above (young, female and educated) are also in line with what has been reported as typical socio-demographics of persons more likely to adopt a vegan and vegetarian diet; as was also observed in the review by Ruby (2012). Nonetheless, as the present study does not aim to provide representative results for the Austrian population, a representative sample is not required. 


\begin{tabular}{ll}
\hline Sample & Means of approach \\
\hline $\begin{array}{l}\text { Facebook groups: Österreich } \\
\text { Vegan; [[ Vegan@Graz ]] }\end{array}$ & $\begin{array}{l}\text { Post of online survey in } \\
\text { Facebook groups, reminder } \\
\text { once a week during collection } \\
\text { period }\end{array}$
\end{tabular}

Restaurants: Café Erde;

Cofeba; Die Erbse

International; Ginko; Go

Nutz Vegan Coffeeshop;

Mangolds; Parks;

Postgarage Cafe; Tischlein

deck dich

Veggie Planet: Verein Gegen

Tierfabriken; Team Vegan

Veggienale: Visitors

University Email System

High school

Other means

Note(s): *as in June 2016
Hard-copy application in restaurants. After contact, cooperation could only be accomplished with Café Erde, Tischlein deck dich and Mangolds

Snow-ball sampling at the fair, access to groups through contact person

Presence during the fair; however, participants during the event were used for the pre-test. Collected e-mail addresses were used for the actual survey

Online access though the university communication system

Contacts established with teacher of a high school

Private distribution and other means
Characteristics

Closed Facebook groups, access only with a Facebook account. Groups that deal solely with vegan topics in Austria, respectively Graz. Österreich Vegan: 5484 members*; [[ Vegan@ Graz ]]: 1577 members* Customers at vegan or vegetarian restaurants located in Graz (Verein Gegen Tierfabriken (VGT), 2016).

Copies of the surveys were placed in prominent places in the restaurants

VGT: members of activist group for animal welfare, number of members or means of survey provision unknown. Team Vegan: vegan sports team in Graz, number of members or other characteristics unknown Fair held in Graz on the 4th and 5th of June (Veggienale, 2015). Fair catered to people interested in a vegan lifestyle and consumption

Email contact with registered students at the University of Graz. Number of students reached, unknown

Age of prospective

participants: $14-18$ years old.

Participation through input of teachers

If possible, participants were encouraged to distribute the survey among friends, family or other interested persons
Return

$n=111$

$(20.00 \%)$

From diet to behaviour

3253

$n=46$

$(8.30 \%)$

VGT

e-mail:

$n=38$

(6.80\%)

Fairs:

$n=14$

$(2.50 \%)$

$n=313$

(56.30\%)

$n=24$

$(4.30 \%)$

$n=10$

(1.80\%)
Table 1.

Sampling strategies and return rates

\subsection{Measurements}

3.3.1 Dietary practices and identities. The vegetarian scale shows that a variety of nutritional practices fall under the umbrella term vegetarianism. The results of previous studies have shown that there is often a discrepancy between an individuals' self-identification, i.e. as a vegetarian, and actual nutritional behaviour, i.e. the consumption of red meat (Rothgerber, 2014). Hence, the first factor that had to be checked was the stated self-estimation of individual nutritional dietary behaviour. The participants were asked to rate their consumption of the following products in an average week: meat, fish or seafood, milk or milk products, eggs or products with eggs. Based on these numbers, the average, selfreported dietary consumption in a year was then calculated. It was only after responses had 


\begin{tabular}{|c|c|c|c|c|}
\hline & & & & \\
\hline $\mathrm{BFJ}_{11}$ & & Characteristic & $n$ & $\%$ \\
\hline & Sex & Male & 113 & 20.30 \\
\hline & & Female & 443 & 79.70 \\
\hline & Nationality & Austrian & 508 & 91.40 \\
\hline & & German & 34 & 6.10 \\
\hline & & Other & 14 & 2.50 \\
\hline 3254 & Highest educational attainment & Compulsory schooling & 5 & 0.90 \\
\hline & & Vocational training & 12 & 2.20 \\
\hline & & Secondary or high school & 226 & 40.60 \\
\hline & & Tertiary education & 313 & 56.30 \\
\hline & Employment status & Student & 305 & 54.90 \\
\hline & & Employees & 184 & 33.10 \\
\hline & & Other & 67 & 12.00 \\
\hline & Place of residence & Graz & 331 & 59.50 \\
\hline & & Vienna & 52 & 9.40 \\
\hline Table 2. & & Other cities & 15 & 2.70 \\
\hline Main sample & & Less than 50.000 inhabitants & 133 & 23.90 \\
\hline characteristics and & & Missing/other & 25 & 4.50 \\
\hline demographics & Total & & 556 & 100 \\
\hline
\end{tabular}

been supplied concerning food consumption that the participants were asked to classify themselves according to the following options: (1) Semi-Vegetarian, (2) Vegetarian, (3) Vegan, (4) Nothing like that, (5) Nothing like that, but reduced consumption of meat and/or animal products, (6) Other.

3.3.2 Motives. Motives can be seen as another cognitive concept influencing dietary choices. Honkanen and colleagues highlighted the relevance of motives influencing food choices in their research, they especially distinguish motives from concepts such as attitudes and believes (Honkanen et al., 2006). Previous studies show that the motives of vegetarians and vegans are not fixed (Ruby et al., 2013), and that they change over time (Stiles, 1998). This was measured through a pair-wise comparison of all four motives where the participants were asked to rate on a nine-point scale which motive influenced them more. A pairwise comparison matrix was then created on the basis of the resulting scores (Saaty, 1996). From the matrix, the multiplied matrix and eigenvalues can be calculated in order to reach the final factor loadings indicating the strengths of each motive. The variable employed in assessing the motives was then used to augment the TPB.

3.3.3 Theory of planned behaviour. The TPB is based on four main concepts: subjective norms, attitude, perceived behavioural control and behavioural intentions. Each one of these concepts had to be operationalised with respect to behavioural categories and to vegetarian or vegan food practices (see Francis et al., 2004). This made it possible to test the TPB with respect to behaviour related to animal well-being and environmental protection.

The calculation of the subjective norm (SN) was altered through the introduction of three reference groups $(g)$ : family, friends and household members. It was possible for participants to indicate 'non-existent'. First, the participant needed to indicate to what degree he/she valued the opinion of reference groups (assessment of the group's opinion $=$ wo). The second item was repeated for each social group; participants had to rate to which degree the social group would think that they should engage in one of the following behavioural activities (i.e. the normative belief $(\mathrm{nb})$ that the group $(g)$ thinks that the subject should engage in behaviour j): 'take care of the environment', 'take care of animals'. This thus made it possible to calculate the perception of subjective norms (SN) on the basis of family, friends and household members as follows: 


$$
\mathrm{SN}_{j}=\sum_{g=1}^{g=3} \mathrm{wO}_{g} \times \mathrm{nb}_{g j}
$$

From diet to behaviour

(adopted from Conner and Norman, 2005)

The participant's attitudes $(A)$ towards the activities were measured directly. Respondents had to rate the two activities $(j)$ according to four dichotomised features $(i)$. These were split along a 5-point scale with the following items at either end: '(for me) pleasant' to '(for me) unpleasant'; 'not very important' to 'very important'; 'very bad' to 'very good'; and 'harmful' to 'beneficial'. Each combination of descriptors represents a different attitudinal measure, such as affective or cognitive attitudes (Honkanen et al., 2006).

$$
A_{j}=\sum_{i=1}^{i=4} a_{i j}
$$

The perceived behavioural control (PBC) consisted of two factors: first, the degree of external control which the person is able to exercise (controllability $=c$ ), and second, the degree to which the person believes in his or her own capacities to perform (self-efficacy $=$ se). Inevitably, there were two measures: self-efficacy and controllability of the behaviour in question (Francis et al., 2004). Both concepts were operationalised by means of a five-point scale: controllability was measured on a range between 'complete control' and 'little control', and self-efficacy was measured with respect to 'very easy' and 'very hard'. Henceforth, the aggregated variable describing perceived behavioural control of behaviour $j$ was computed as follows:

$$
\mathrm{PBC}_{j}=\mathrm{se}_{j} \times c_{j}
$$

3.3.4 Behavioural commitment. Behaviour with regard to the two main categories (animal well-being and environmental protection) was mainly measured in terms of the frequency that participants engage in certain activities. Depending on the behaviours, a more or less frequent engagement is interpreted as a pro or contra position with respect to the behavioural category. For instance, frequent car usage was interpreted as environmentally harmful behaviour. The actual causation of harm or the prevention of it remains undefined. The complete overview of the measured environment-related behaviour is listed in Table 3.

The behavioural categories describing activities related to animal welfare can be found in Table 4 . With regard to hobbies, statements about them needed to be rated on a five-point scale, indicating whether the participants agree with them or not. Additionally, the frequency of the consumption of other non-dietary, animal-derived products was also measured, e.g. that of fur, leather or feathers.

\begin{tabular}{llll}
\hline Resources & Groceries consumption & Clothes consumption & Transportation \\
\hline
\end{tabular}
(1) Recycling
(2) Waste reduction
(3) Energy consumption
$\begin{array}{ll}\text { (1) } & \text { Organic } \\ \text { (2) } & \text { Regional } \\ \text { (3) } & \text { Certification }\end{array}$
(1) Organic
(2) Regional
(3) Certification
(4) Second-Hand
(1) On Foot
(2) Bicycle
(3) Motorbike
(4) Public transportation
(5) Train
(6) Long distance Bus
(7) $\mathrm{Car}$
(8) Car sharing
(9) Plane

Table 3.

Behaviour categories and items of environment-related behaviour measures 
$\mathrm{BFJ}$

122,11

\section{6}

Table 4.

Behaviour categories and items of animalrelated behaviour measures

\subsection{Analysis}

The measurements and calculations created a mainly non-parametric and non-normally distributed dataset; Spearman's correlation coefficient $\left(r_{s}\right)$ can be used for exactly such cases. The difference in the dietary groups can be evaluated through a comparison of the respective mean values. The statistical computations were conducted using the software IBM SPSS Statistics 23.

\section{Results and discussion}

The final sample of the survey consists of 556 completed questionnaires, coming from all different sampling methods (see Table 1). The data from the hard-copy surveys at the restaurants was entered manually by the researchers in order to achieve data consistency. As there were no exclusionary criteria, all completed surveys were considered in the analysis. However, some of the analyses were based on specific selection criteria or parameters.

\subsection{Limitations}

As the sampling method was designed to capture as many vegetarians and vegans as possible, no claim is made in terms of population representativeness. In addition, it also needs to be noted that as vegetarian and vegan diets are highly individual and personal practices, general statistics on vegetarian and vegan populations are largely estimates. Because of this individual execution of their diet, there are hardly any gathering points of exclusively vegetarians or vegans. These circumstances leave the researcher no other option than to cover several recruitment strategies where a higher presence of vegetarians and vegans can be assumed. Nevertheless, the final sample obtained is believed to be satisfactory. Online and hard copy surveys were used as polling method and this methodological choice also entails specific limitations.

The validity of theoretical concepts and statistical tests is always subject to various assumptions. The collected data set shows its own individual patterns and characteristics, and its own inherent limitations. Overall, the data shows a tendency towards a non-normal distribution and is of a non-parametric nature. The applied level of abstraction represents a further form of constraint in terms of question design. However, all theoretical models contain abstractions and simplifications and in that sense, can be good or bad mechanisms for capturing reality. As the operationalisation of the TPB requires a relatively high level of abstraction a lot of detailed information was lost as a result.

The focus of this study is to investigate the bridge from motivation to behaviour, where a selection of key motives and behaviour was queried in a survey. Fundamentally, the nature of this relationship was investigated through this research. It provides a first glance into motivational decisions with regard to food choices and their connection to behaviour outside of the spectrum of food choices. However, external factors which could impact and form this

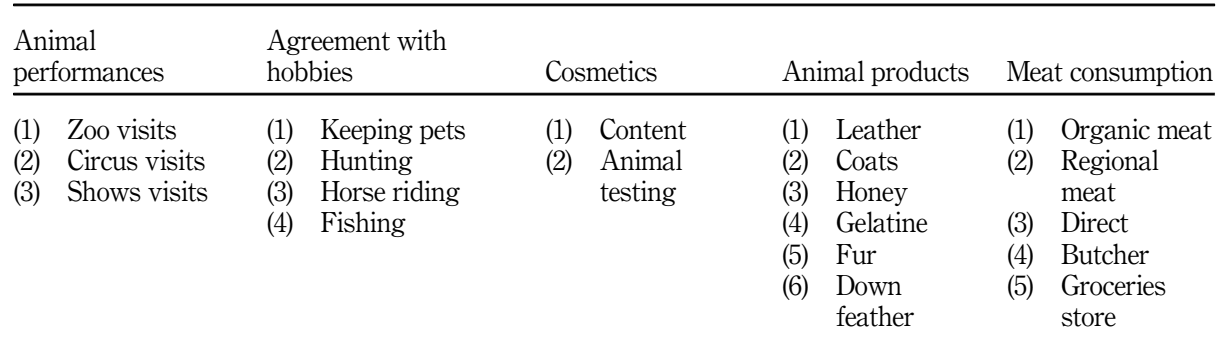


relationship in different ways are only considered marginally. Only a small variety of external factors were briefly touched upon; remaining factors could be the increasing public discourse, more knowledge about vegetarian or vegan celebrities or a higher social acceptance.

\subsection{Dietary practices and identities}

Unexpectedly, the sample consists of more vegans $(25.70 \%)$ than vegetarians $(16.70 \%)$. Because vegetarianism is the less strict practice, the lower number of vegetarians appears unusual. Nonetheless, with $29.70 \%$, the conscientious omnivores are the biggest group in the sample, followed by the omnivores with $26.60 \%$. Seven participants $(1.30 \%)$ did not identify with any of the given categories.

However, as other studies have shown, self-identification does not necessarily conform to actual dietary practice (Barr and Chapman, 2002; Robinson-O'Brien et al., 2009; Ruby, 2012; Worsley and Skrzypiec, 1998), which could be confirmed with this sample. Figure 2 illustrates the consumption patterns of the participants in terms of the different dietary groups.

The consumption of fish and seafood appears to be quite high among vegetarians, this is possibly due to the popular form 'pescetarian', in comparison to other food groups, the average consumption of fish and seafood products by the vegan group is still relatively low. This can probably be explained in terms of traditional Austrian cuisine, where the share of fish and seafood is generally rather low. Although, by definition, the conscientious omnivore's and vegetarian's diet does not restrict the consumption of milk or egg products, both still score lower than the omnivore. Differences in the consumption frequency of honey, and of products with gelatine, are not very extreme, although, overall, the general rule still applies that the stricter the diet the lower the consumption frequency. Consumption patterns of individuals who live in a shared household might be influenced by the other household members, i.e. the person who is mainly responsible for doing groceries or preparing meals. This could impact the consumption data in both ways: increased or decreased consumption based on external availability.

\subsection{Motivational drivers}

The AHP analysis and the comparisons of the various motives result in the following factor loadings: $43.80 \%$ animal welfare motives, $29.08 \%$ environment motives, $18.11 \%$ health motives and $9.00 \%$ taste motives. This confirms what other authors (e.g. Janda and Trocchia, 2001; Beardsworth and Keil, 1992) have already shown: animal welfare motives are the strongest motivational trigger, followed by environmental motivations. Health and taste motivations are a little less relevant.
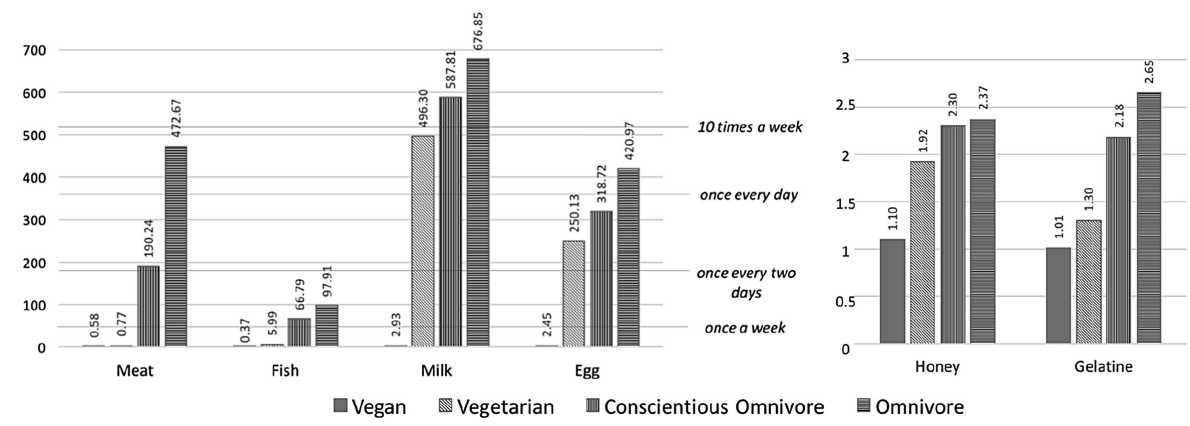

From diet to behaviour

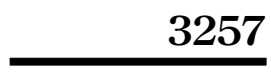

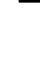


BFJ 122,11

\section{8}

Figure 3.

Results of the theory of planned behaviour with regard to animalrelated behaviour
The AHP provides a unique approach to establishing the motive weights of vegetarians and vegans and shows that, overall, participants' drivers are not necessarily explained in terms of any single motive. Research on motive structures often describes the main motive(s) without further assessment. However, Ruby et al. (2013) pointed out that motives also change over time and Stiles (1998) indicated that they increase. Clearly, dietary choice depends simultaneously on several motivational drivers. The AHP permits a comparison and an evaluation based on relative measures, and thus may be used to account for the influence of several factors.

The factor loadings were included in the design as an extension of the TPB. This extension and its relatively high significance also highlight the shortcomings of the TPB. Research on vegetarianism and veganism has shown that their motivations are strong behavioural predictors. This could be confirmed by contrasting the motivational factors with the concepts of the TPB. Within statistical tests the motivational variables show a similar magnitude in statistical relevance.

\subsection{Animal-related results}

4.4.1 Theory of planned behaviour and animal-related results. The statistics describing the bivariate correlation analysis of the concepts from the theory of planned behaviour with respect to animal-related behaviour can be found in Figure 3. The analysis of all participants generated a high amount of significant correlations. However, only relatively few of these significant correlations explain much of the variability in the other variables; the highest level of explained variability is that relating to perceived behavioural control and intentions, at $31.00 \%$. The coefficient of determination of the subjective norms is relatively low compared to that of the other concepts, at $r_{s}=0.14$. The low statistical relevance of the subjective norms could be related to the fact that a vegetarian or vegan diet does not conform to the general dietary norms. Hence, norms may not be such an influential factor as they already behave outside of the common norm. The respective significance values, and hence also $r_{s}$, of the motives, matches that of the other concepts in explaining behaviour from a statistical perspective. While attitude strongly correlates with behavioural intentions, the correlation between attitude and behaviour is not as large. It seems that attitude can explain more of the intentions than of the actual behaviour.

4.4.2 Behavioural commitment and animal-related results. The overall reliability of the animal-related behaviour variable is not especially high, Cronbach's $\alpha=0.64$. This could be explained by the large differences in the respective mean values obtained for the five items used, which range from a mean of 2.98 (meat consumption) to 4.62 (animal performance), see Figure 4 for an illustration. Additionally, the mean values obtained for each dietary group are added and connected. The variable on the consumption of meat is only applicable to the meatconsuming dietary groups.

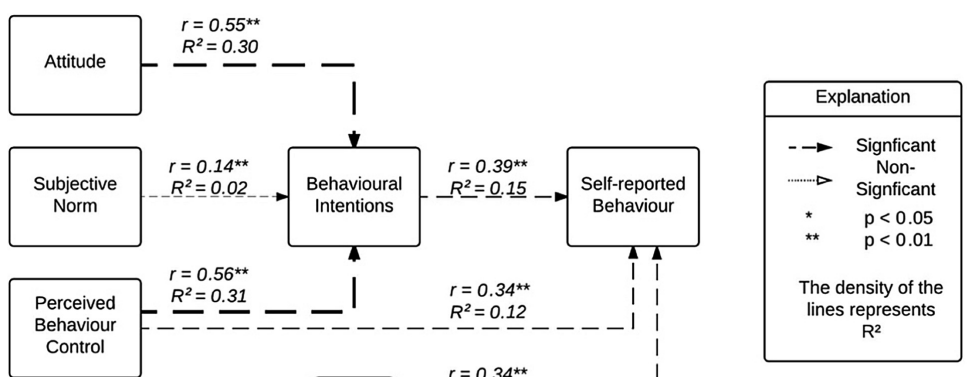




\section{$\multimap$ All \\ $-\Delta$-Vegetarians \\ $\rightarrow$. Omnivores}

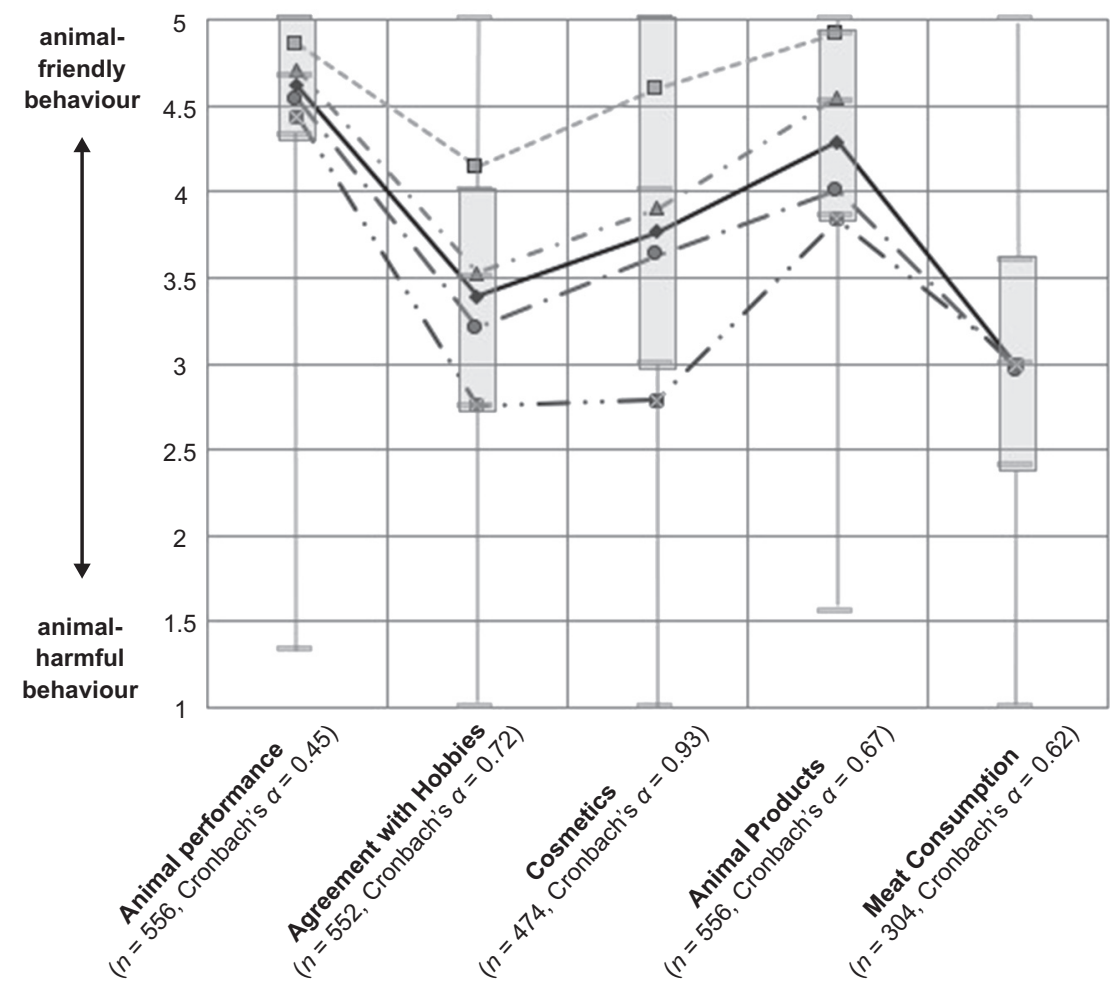

From diet to behaviour

3259

Figure 4.

Self-reported behaviour of animalrelated activities ( $n$ of items $=5$, Cronbach's $\alpha=0.64$ ) in relation to dietary choices

Although the dispersion of the animal performance variable covers almost the whole range, there appears to be strong skewness, as the second and third quartiles are relatively small and at the higher end of the scale. It is striking that the mean value obtained for the vegans is the only one that is above the median almost continually throughout the different activities. However, the high mean scores (which mean an infrequent engagement) could be the result of the fact that animal performances are in general relatively unpopular, and/or that, in normal daily life access to such performances (e.g. a circus) is rather limited or infrequent.

The variable describing attitudes towards hobbies is dispersed throughout the whole scale and appears less skewed. The mean score of the vegans is already in the fourth quartile, indicating that they are located at the higher extreme of the scale, or are almost an outlier.

The consumption of cosmetics with regards to animal testing and animal-based ingredients covers again the whole range. However, the first quartile is stretched out over the lower half of the scale $(<3)$. The mean scores of the omnivores are also located within the lower $25 \%$ of the data. Again, high skewness at the higher end of the scale was found, indicating that the participants had a tendency to achieve more animal-friendly scores. The scores with regard to consumption of other animal products show a similar pattern to that described above. 
$\mathrm{BFJ}$ 122,11

\section{0}

Figure 5.

Results of the theory of planned behaviour with regard to environment-related behaviour
The variable describing meat consumption is only applicable to the non-plant-based groups. The dataset shows no difference between the omnivore and the conscientious omnivore.

Generally speaking, the average scores increase with the increasing strictness of the diet. Cherry (2006) highlighted that vegans exclude animal products not only in their diet, but also in their lifestyle, hence, creating a wider behavioural impact. This increased commitment is also observable in this research: the more animal-friendly the diet, the more animal-friendly the behaviour. There also appears to be a separation in the data in terms of the mean values of all participants: values for the plant-based diets are above the general mean, whereas for diets incorporating meat values are below the overall mean value.

\subsection{Environment-related results}

4.5.1 Theory of planned behaviour and environment-related results. The analysis of the concepts from the theory of planned behaviour exemplifies that while all concepts appear to correlate significantly, the magnitude of these correlations varies (see Figure 5). The weakest connection can be found between the subjective norms and the intentions, evidencing a shared variability of only $1.00 \%$. In contrast, the other concepts share between $13.00 \%$ and $27.00 \%$ of their variability with the intentions and behaviour variables. In this instance, motives appear to be somewhat less relevant than other concepts. De Leeuw and colleagues (De Leeuw et al., 2015) found the framework of the TPB to be a statistically significant framework to describe pro-environmental behaviour among high school students; similarly to this result, the reported effect of norms was smaller compared to other concepts.

4.5.2 Behavioural commitment and environment-related results. The analysis based on different dietary groups reveals the same general pattern as that found for the animal-related domain: the stricter the diet the higher the scores (see Figure 6). Here, however, the divergence between the mean scores of the different groups is not as distinct as before. Generally, the mean values are much closer and may even overlap. Consequently, the higher score obtained by the vegans may not be that meaningful, because of the small gap to the other groups. However, the mean scores for the omnivores are consistently lower than the scores obtained by others.

The variable describing resource usage appears to be skewed towards the higher end of the scale, and the lower scores are not completely exhausted. Although small, the pattern concerning the hierarchy of the dietary groups could also be found here.

The behaviour related to grocery consumption shows a similar structure, and the data is disbursed over the whole scale. The vegans, vegetarians and conscientious omnivores

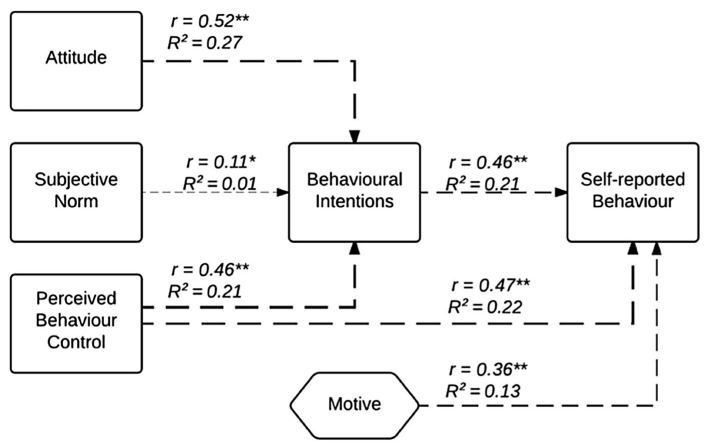




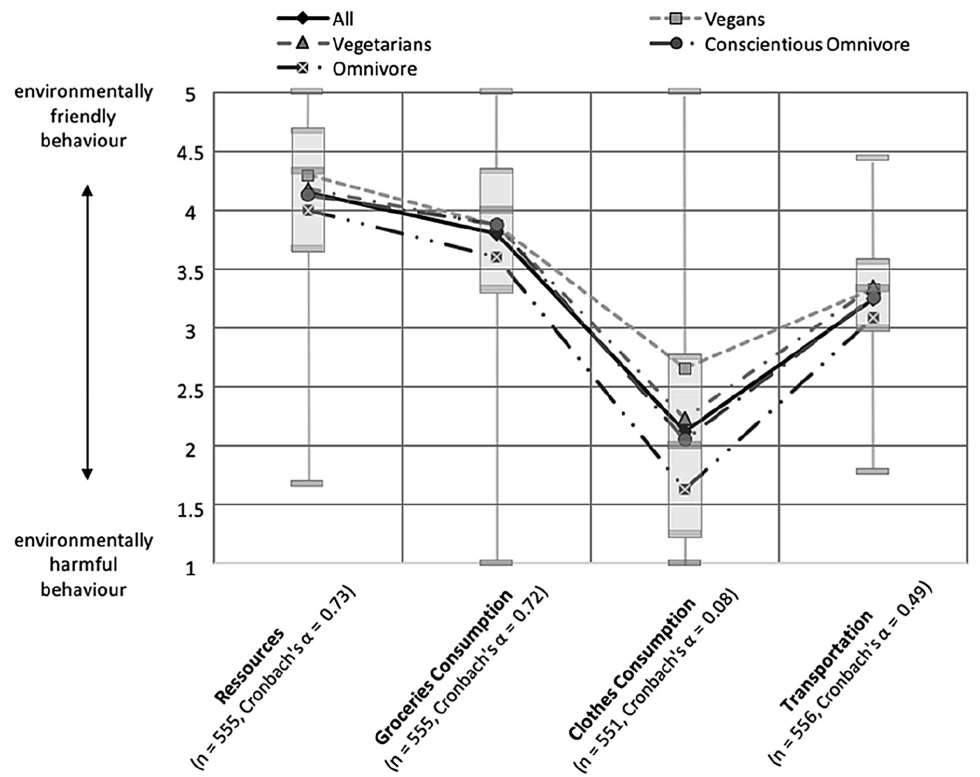

From diet to behaviour

3261

Figure 6.

Self-reported

behaviour of environment-related activities ( $n$ of items $=4$, Cronbach's $\alpha=0.64)$ in relation to dietary choices

achieved almost the same mean value (3.87 and 3.88), while the omnivores score somewhat lower with a mean of 3.60. Again, the differences in terms of the dietary groups are rather small and even the previously observed group hierarchy does not apply here.

With regards to clothes consumption the data dispersion shows an entirely different picture compared to all the other observations. First, the data is skewed towards the lower end of the scale, it exhibits a trend opposite to that found in the other results. The inner $50 \%$ of the data are all below the middle score of three, and occupy the 'environmentally harmful' side of the scale. This indicates that the participants do not intensively explore options in terms of organic, regional, certified and second hand-clothing. This difference in behaviour could be the result of the fact that both the level of awareness and the existing possibilities with respect to certain environmentally friendly activities are stronger in some behavioural domains than in others. Nonetheless, the hierarchy of the dietary groups shows the previously observed pattern: the stricter the diet, the higher the scores.

The measured mode of transportation is rather close to the middle range of the scale and the variance of the scores is rather small. Also, the mean values of the dietary groups are all within a small range, between 3.09 (omnivores) and 3.35 (vegetarian). The low reliability of the transportation variable might be due to the many types of transportation available, which created a higher level of variability and inconsistency within the data.

The previously observed trend found with respect to animal-related behaviour can not entirely be detected with regard to environmental-related behaviour. The tendency towards supportive behaviour is not as clear, and also the hierarchy with respect to the group mean values is not the same. However, these differences in behavioural commitment can be partly explained by the respective motives of the vegetarians and vegans. $65.73 \%$ of the vegans and $59.14 \%$ of the vegetarians adopted their diets for animal-related reasons. It therefore stands to reason that their commitment within this area is also stronger. Fox and Ward (2008a) pointed out that vegetarians express their driving philosophy in their 'life-style', a similar pattern was observed within the two defined behavioural domains. Similarly, Phillips (2005) indicated that the system of beliefs underpinning vegetarianism infuses with their life-style. 
BFJ

122,11

The low significance of the subjective norms in both behavioural domains indicates what also Stoll-Kleemann and Schmidt (2017) pointed out: norms can create barriers to dietary change. Vice versa, the vegetarian and vegan diet is also one usually considered outside of the norm.

\section{Conclusions}

This research covers a wide spectrum of matters related to the behavioural sphere of vegetarianism and veganism. This behavioural sphere has been split up into several domains: (1) dietary habits; (2) behavioural activities related to animal welfare; and (3) activities and habits related to environmental protection and sustainability (with both behavioural activities based on underlying ethical assumptions). With the help of the TPB, insights were gained concerning the connections between the underlying motives that drive the individual to become vegetarian or vegan and the associated behavioural domains. To date, research on vegetarianism and veganism has almost never reached out to cover associated behavioural commitment. Instead, researchers have focused on factors directly related to the individual, or to the actual practice of vegetarianism and veganism. The new perspective presented here may be used to shed light on relevant external issues. These external issues addressed in this paper are restricted to specific areas of behaviour. However, dietary choices, veganism and vegetarianism could still be subjected to many other external influences which remain unexplored. Current developments with increased public discourse and awareness on the subject matter could be one of these factors.

The theory of planned behaviour provided a suitable theoretical foundation. A dietary change such as a move towards vegetarianism and veganism requires that the individual makes a conscious decision. Additionally, analysis of the respective strengths of the background motives was merged with the TPB. This served to expose the potential links between motives and behaviour, and helped raise the credibility of the whole analysis. It was shown that the motives themselves could generally explain just as much as the other TPB concepts. These results also point towards the shortcomings of the TPB. The statistical relevance of the motives illustrates that they can achieve similar statistical relevance as the original concepts from the TPB. One source of uncertainty lies in the relationship between motives and predictive power, as the measured motives may not be mutually exclusive of other TPB concepts. Overall, it was found that TPB analysis supports the assumption that motives play an important role with regard to the behavioural expressions of vegetarians and vegans.

A closer look at the behaviour reveals that the behavioural patterns vary among dietary groups. The level of commitment turns out to be stronger the stricter the dietary category is. Through a stricter diet, vegans express a stronger conviction and this is reflected in their behaviour. As the animal-related and environment-related motives are the key drivers in the vegetarian and vegan sample, the behavioural differences in these domains are noteworthy. It can thus be deduced that dietary choice corresponds to a strong commitment to the basic motives underlying the adoption of a vegetarian and vegan lifestyle in other behavioural spheres of activities. The gained insights question the vegetarian and vegan categories as purely dietary-based terminologies. Although the identity may originate from food consumption choices, the related behavioural commitment exceeds the dietary sphere. This indicates that vegetarians and vegans are not only a specific group of food consumers, but describe a group whose behavioural patterns are guided by wider ethical considerations.

This research has attempted to move beyond direct analysis of vegetarian and vegan dieting into the associated environmental behavioural spheres of activity. It managed to demonstrate the link between motives and behaviour. In a nutshell, vegetarians 
and vegans reveal their ethical convictions not only in terms of their dietary choices but also in terms of their commitment to their underlying motives in non-dietary behaviour.

\section{References}

Aertsens, J., Verbeke, W., Mondelaers, K. and Van Huylenbroeck, G. (2009), "Personal determinants of organic food consumption: a review", British Food Journal, Vol. 111 No. 10, pp. 1140-1167.

Ajzen, I. (1991), "The theory of planned behavior", Organizational Behavior and Human Decision Processes, Vol. 50 No. 2, pp. 179-211.

Ajzen, I. (2011), "The theory of planned behaviour: reactions and reflections", Psychology \& Health, Vol. 26 No. 9, pp. 1113-1127.

APA-OTS (2013), "Neueste IFES studie bestätigt veggie-boom: 9\% VegetarierInnen in österreich!", available at: http://www.ots.at/presseaussendung/OTS_20130821_ots0142/neueste-ifes- studiebestaetigt-veggie-boom-9-vegetarierinnen-in-oesterreich (accessed 8 April 2017).

Barr, S.I. and Chapman, G.E. (2002), "Perceptions and practices of self-defined current vegetarian, former vegetarian, and nonvegetarian women", Journal of the American Dietetic Association, Vol. 102 No. 3, pp. 354-360.

Beardsworth, A. and Keil, T. (1992), "The vegetarian option: varieties, conversions, motives and careers", The Sociological Review, Vol. 40 No. 2, pp. 253-293.

Berndsen, M. and Van Der Pligt, J. (2004), "Ambivalence towards meat", Appetite, Vol. 42 No. 1, pp. 71-78.

Campbell-Arvai, V., Arvai, J. and Kalof, L. (2014), "Motivating sustainable food choices: the role of nudges, value orientation, and information provision", Environment and Behavior, Vol. 46 No. 4, pp. $453-475$.

Cherry, E. (2006), "Veganism as a cultural movement: a relational approach", Social Movement Studies, Vol. 5 No. 2, pp. 155-170.

Conner, M. and Armitage, C.J. (1998), "Extending the theory of planned behavior: a review and avenues for further research", Journal of Applied Social Psychology, Vol. 28 No. 15, pp. 1429-1464.

Conner, M. and Norman, P. (2005), Predicting Health Behaviour, McGraw-Hill Education, Maidenhead, Berkshire.

De Leeuw, A., Valois, P., Ajzen, I. and Schmidt, P. (2015), "Using the theory of planned behavior to identify key beliefs underlying pro-environmental behavior in high-school students: implications for educational interventions", Journal of Environmental Psychology, Vol. 42, pp. 128-138.

Fleskens, L. and Jorritsma, F. (2010), "A behavioral change perspective of maroon soil fertility management in traditional shifting cultivation in Suriname", Human Ecology, Vol. 38 No. 2, pp. 217-236.

Forestell, C.A., Spaeth, A.M. and Kane, S.A. (2012), "To eat or not to eat red meat. A closer look at the relationship between restrained eating and vegetarianism in college females", Appetite, Vol. 58 No. 1, pp. 319-325.

Fox, N. and Ward, K. (2008a), "Health, ethics and environment: a qualitative study of vegetarian motivations", Appetite, Vol. 50 No. 2, pp. 422-429.

Fox, N. and Ward, K. (2008b), "You are what you eat? Vegetarianism, health and identity", Social Science \& Medicine, Vol. 66 No. 12, pp. 2585-2595.

Francis, J., Johnston, M., Eccles, M., Walker, A., Grimshaw, J., Foy, R., Kaner, E.F.S., Smith, L. and Bonetti, D. (2004), "Constructing questionnaires based on the theory of planned behaviour: a manual for Health Services Researchers", Quality of life and management of living resources, Centre for Health Services Research, available at: http://openaccess.city.ac.uk/id/eprint/1735.
From diet to behaviour 
BFJ 122,11

Honkanen, P., Verplanken, B. and Olsen, S.O. (2006), "Ethical values and motives driving organic food choice", Journal of Consumer Behaviour, Vol. 5 No. 5, pp. 420-430.

Janda, S. and Trocchia, P.J. (2001), "Vegetarianism: toward a greater understanding", Psychology and Marketing, Vol. 18 No. 12, pp. 1205-1240.

Mateo, J.R.S.C. (2012), "The renewable energy industry and the need for a multi-criteria analysis", Multi Criteria Analysis in the Renewable Energy Industry, Vol. 83, pp. 1-5.

Nosek, B.A., Banaji, M.R. and Greenwald, A.G. (2002), "Research: ethics, security, design, and control in psychological research on the internet”, Journal of Social Issues, Vol. 58 No. 1, pp. 161-176.

Peattie, K. (2010), "Green consumption: behavior and norms", Annual Review of Environment and Resources, Vol. 35 No. 1, pp. 195-228.

Phillips, F. (2005), "Vegetarian nutrition”, Nutrition Bulletin, Vol. 30 No. 2, pp. 132-167.

Pimentel, D., Williamson, S., Alexander, C.E., Gonzalez-Pagan, O., Kontak, C. and Mulkey, S.E. (2008), "Reducing energy inputs in the US food system", Human Ecology, Vol. 36 No. 4, pp. 459-471.

Povey, R., Wellens, B. and Conner, M. (2001), "Attitudes towards following meat, vegetarian and vegan diets: an examination of the role of ambivalence", Appetite, Vol. 37 No. 1, pp. 15-26.

Radnitz, C., Beezhold, B. and DiMatteo, J. (2015), "Investigation of lifestyle choices of individuals following a vegan diet for health and ethical reasons", Appetite, Vol. 90, pp. 31-36.

Robinson-O'Brien, R., Perry, C.L., Wall, M.M., Story, M. and Neumark-Sztainer, D. (2009), "Adolescent and young adult vegetarianism: better dietary intake and weight outcomes but increased risk of disordered eating behaviors", Journal of the American Dietetic Association, Vol. 109 No. 4, pp. 648-655.

Rothgerber, H. (2014), "A comparison of attitudes toward meat and animals among strict and semivegetarians", Appetite, Vol. 72, pp. 98-105.

Rothgerber, H. (2015), "Underlying differences between conscientious omnivores and vegetarians in the evaluation of meat and animals", Appetite, Vol. 87, pp. 251-258.

Rozin, P., Markwith, M. and Stoess, C. (1997), "Moralization and becoming a vegetarian: the transformation of preferences into values and the recruitment of disgust", Psychological Science, Vol. 8 No. 2, pp. 67-73.

Ruby, M.B. (2012), "Vegetarianism. A blossoming field of study”, Appetite, Vol. 58 No. 1, pp. 141-150.

Ruby, M.B., Heine, S.J., Kamble, S., Cheng, T.K. and Waddar, M. (2013), "Compassion and contamination. Cultural differences in vegetarianism”, Appetite, Vol. 71, pp. 340-348.

Saaty, T.L. (1996), The Analytic Network Process, RWS Publications, Pittsburgh.

Sniehotta, F.F., Presseau, J. and Araújo-Soares, V. (2014), Time to Retire the Theory of Planned Behaviour Health Psychology Review, Vol. 8 No. 1, pp. 1-7.

Stiles, B. (1998), "Vegetarianism: identity and experiences as factors in food selection", Free Inquiry in Creative Sociology, Vol. 26 No. 2, pp. 213-226.

Stoll Kleemann, S. and Johanna Schmidt, U. (2017), "Reduzierter Fleischkonsum als Vehikel für die große Transformation: Voraussetzungen und Realisierungschancen”, GAIA: Ecological Perspectives for Science and Society, Vol. 26 No. 4, pp. 364-365.

Tanner, C., Kaiser, F. and Wöfing Kast, S. (2004), "Contextual conditions of ecological consumerism”, Environment and Behavior, Vol. 36 No. 1, pp. 94-111.

Veggienale (2015), "Veggienale - messe für vegane Lebenskultur", available at: http://veggienale.de (accessed 23 April 2016).

Vermeir, I. and Verbeke, W. (2006), "Sustainable food consumption: exploring the consumer 'attitude behavioral intention' gap”, Journal of Agricultural and Environmental Ethics, Vol. 19 No. 2, pp. 169-194. 
VGT (2016), "Vegetarisch/Vegane gastronomie", available at: http:/vgt.at/service/vegetarismus/ restaurants/index.php (accessed 19 April 2016).

Wansink, B. and Sobal, J. (2007), "Mindless eating", Environment and Behavior, Vol. 39 No. 1, pp. 106-123.

Worsley, A. and Skrzypiec, G. (1998), "Teenage vegetarianism: prevalence, social and cognitive contexts", Appetite, Vol. 30 No. 2, pp. 151-170.

YouGov Deutschland, A.G. (2014), "Wer will's schon vegan. Aktuelle Ernährungsvorlieben und Lieblingsmarken in Deutschland 2014-Typ für Typ”, available at: https:/yougov.de/loesungen/ reports/studien/vegan-studie/ (accessed 21 August 2016).

\section{Corresponding author}

Tobias Stern can be contacted at: tobias.stern@uni-graz.at

For instructions on how to order reprints of this article, please visit our website: 